\title{
The Use of Information and Communication Tools to Teach Particulate Nature of Matter: A Study of a Science Class
}

\author{
Frederick Ameyaw \\ Department of Science, Bagabaga College of Education, P.O. Box 35 ER, Tamale-Ghana
}

\begin{abstract}
This paper deals with the use of information and communication tools to teach particulate nature of matter in a Science class at Guakro Effah Senior High School in the Techiman North District of Ghana. The research design used for the study was action research. A sample of 35 students were selected for the study using convenience sampling technique. The instrument used for gathering data were test and observation. Information and communication tools were used to teach the students during the intervention. Data collected was analysed with descriptive and inferential statistics. The findings revealed that students understand abstract concepts better when information and communication tools were used to teach, students' performance improved and they were motivated during Chemistry lesson when information and communication tools were used to teach. The study recommends the need to use information and communication tools to teach abstract concepts in chemistry and the need to priorities in-service training and seminars for Science teachers to improve on their skills in order to use information and communication tools in delivery of their lessons effectively.
\end{abstract}

Keywords: Information, Communication tools, Particulate Nature of Matter

DOI: $10.7176 / \mathrm{JEP} / 11-13-11$

Publication date:May $31^{\text {st }} 2020$

\section{Introduction}

Researches in Science Education show that students have difficulty in acquisition of abstract scientific concepts (Özcan, 2003; Çimer, 2004; Saka, 2006; Zeidan, 2010). Many Senior High School students experience difficulties with fundamental concepts in Chemistry. Chemistry deals with chemicals and their reactions most of which are very dangerous to life if not handled with caution. Reactions of these chemicals in most cases are not easy to understand by students without seeing them in real term. Teachers usually explain these reactions abstractly and through molecular diagrams. Despite the importance of the foundation of Chemistry, most students emerge from introductory courses with very limited understanding of the subject. Chemistry had been regarded as a difficult subject for students by many researchers, teachers and science educators because of the abstract nature of many chemical concepts, teaching styles applied in class and lack of teaching aids. Atomic Structure is one of the Chemistry concepts, often identified as basic fundamental concepts for mastering further understanding (Francisco, Nakhleh, Nurrenbern, \& Miller, 2002; Niaz, Aguilera, Maza, \& Liendo, 2002; de Jong \& Taber, 2007; Park \& Light, 2009). Atomic Structure is among some Chemistry topics which are taught abstractly by many Senior High School Science Teachers. Park and Light (2009) have studied the concept of atomic structure and maintained that one problem with previous research has been focused on students' difficulties, while not providing advice to teachers how to proceed and solve these difficulties.

Huffman, Goldberg and Michlin (2000) recognised that using Information and Communication Technology (ICT) could involve a different teaching and learning style from that of the traditional, didactic approach. ICT has become within a short time one of the basic building blocks of a modern society. Many countries now regard understanding ICT and mastering its basic concepts as part of the core of education (UNESCO, 2002). The use of ICT tools is important in teaching and learning process as it increases learner's motivation, makes students to understand better abstract concepts, allows collaborative learning and provides the opportunity for learning through simulation. Appropriate use of ICT simulations helped significantly to improve students' understanding of Science ideas compared with the use of non-ICT teaching activities. Tchombe (2008) asserted that ICT tools if used appropriately can stimulate the development of higher cognitive skills, deepen learning and contribute to the acquisition of skills needed for learning all lifelong. Using ICT tools in teaching Science lesson can also help students to understand Science concepts through a relationship with a real-life situation. ICT improves educational outcomes and enhances quality of teaching and learning (Wagner, 2001).

\section{Statement of the Problem}

The Researcher's observation shows that Science students in Guakro Effah Senior High School do not grasp Chemistry concepts when lecture method is used in teaching. Lecture method of teaching is not suited for teaching higher order of thinking such as application, analysis, and synthesis (Sze-yin, 2015). Students resort to memorising abstract concepts since they find it difficult understanding it meaningfully hence leading to their low performance in Chemistry (Krah, 2014). It is against this background that the researcher wants to find out the effect of information and communication tools on the learning outcomes of students. 


\section{Purpose of the Study}

The purpose of the study is to find out the effect of information and communication tools on the learning outcomes of students in Chemistry.

\section{Theoretical framework}

The study was guided by Cognitive Theory of Multimedia Learning (Mayer, 2009), the cognitive process of integrating is most likely to occur when the learner has corresponding pictorial and verbal representations in working memory at the same time. Mayer (2009) posited that, the computer is a system for delivering information to learners and learning involves adding information to one's memory. The instructional designer's role is to present information (e.g. pictures, word, videos) and the learner's role is to receive the information. As some students prefer visual presentations, other students may prefer verbal presentations. Therefore, multimedia presentations would be effective in delivering information effectively to both kinds of students and they could select their delivery way. Information and Communication tools create a powerful virtual learning environment and it transforms the learning and teaching process in which students deal with knowledge in an active, selfdirected and constructive way and can help deepen students' content knowledge, engage them in constructing their own knowledge, and support the development of abstract thinking skills.

\section{Methodology}

In this study, action research design approach was adopted and this design sought to find out students' conceptual understanding about the structure of the atom. Then the study also used intervention lessons with information and communication tools to correct the misconceptions held by students on the structure of the atom. The population for the research consisted of all first year Senior High School students in Techiman North District of Ghana. The accessible population was all the first-year Science students of Guakro Effah Senior High School at Offuman.

\subsection{Sample and sampling Procedure}

The sample size was 35 students and out of these, 25 of them were boys and 10 girls. Convenience sampling technique was used because, all the student's in General Science class were used to conduct the research.

\subsection{Research Instruments}

The data collection method employed was test (pre-intervention test and post-intervention test). A pre- intervention test was conducted to find students basic knowledge in the Structure of Atom. This enabled the researcher get to know the students' prior knowledge on the Structure of Atom. A post-intervention test was conducted to assess the students' newly acquired knowledge of the Atom. The pre-intervention and post-intervention tests were sampled from test books and past questions of West African Secondary School Certificate Examination (WASSCE). A 20 -item test questions on knowledge, comprehension and application, made up of 8 multiple choice, 8 true or false and 4 essays typed were used to collect data from respondents before and after the intervention.

\subsection{Validity and Reliability}

Content validity was employed in the test to measure the intended content area since a test must measure what it claims to measure, in order to be considered valid (Alhoward, 2015) as cited in Ansah (2015). In doing this the test items in the instrument were compared with questions in the Chemistry syllabus on the selected topics and was given to a colleague Science teacher and a lecturer at the Department of Science Education, University of Education, Winneba to be scrutinized. It was then confirmed to be within the level of the respondents and so was permitted to administer the items. The test items were piloted on form one General Science students of the same school and Alpha (Cronbach) coefficients was used to calculate for the components of each measurement scale to verify internal consistency. The pilot study obtained coefficient relations of 0.6 , which made the test items to be considered reliable according to Kothari (2004) who confirms that reliability of 0.6 is adequate.

\subsection{Data Collection Procedure}

In this study, data was collected with the aid of the research instruments test and class observation. The data collection procedure was divided into three phases: pre-intervention, intervention and the post intervention phase. The test and observation were conducted by the researcher in the school.

\subsection{Pre-intervention phase}

This stage of the study lasted for a week. The Researcher informed the headmaster about the research work he wanted to carry out in the school in order to solicit his cooperation and assistance. He then liaised with the headmaster to get ICT tools (computer and projector) and a stand by generator in case of power outage. Lesson notes were prepared. 


\subsection{Intervention phase}

This phase had to do with the implementation of the intervention. The stage lasted for two weeks. The researcher delivered the lessons with the aid of the ICT tools.

The researcher monitored students' attitude during the intervention with guidelines from the observation checklist. The researcher wrote observational note after each lesson.

\subsection{Post-intervention phase}

This was the final phase which was mainly used to test students to find out if the intervention was successful. The test was marked and collated for analysis.

This stage lasted for a week.

\subsection{Data Analysis procedures}

In this study, data analysis procedure that was employed was both Qualitative and Quantitative procedures. Quantitative data that was obtained from the Pre-intervention and Post-intervention test were analysed using descriptive analysis by Comparing Students' Mean Performance based on the profile dimension (Knowledge, Comprehension and Analysis) of both Pre-test and Post-test, described by Sarantakos (2005) as a type of analysis that aims at identifying and describing the main content of data and inferential statistics. Qualitative data were presented in report on the lessons and analysed based on the progress of the students from lesson to lesson. The activities carried out, the interactions, the level of participation in the lessons and the progression of the lessons were all grounded in the report. The observations made during the lessons and findings from the lessons were analysed. Discussions of the findings were made based on the research questions. On the basis of analysing the findings, conclusions and recommendations were made.

\section{Results/Discussions}

With the Research question on what scientific perceptions do students have about particulate nature of matter? From the observation made, the researcher has observed that Chemistry students' in Guakro Effah Senior High School:

- appear to be unable to answer questions when it comes to Structure of the Atom. They have the perception that Chemistry is very difficult. The difficulty is caused by their inability to interpret concepts being taught abstractly or verbally without visuals images.

- were able to define concepts but could not explain how the concept was formed. The researcher asked students to define an ion and most of them were able to define ion but could not explain how ions are formed from Atoms. The classroom interactions that occurred between the researcher and the students were analysed. These results seem consistent with the statement by some researchers that the understanding of chemical concepts does not only involve rote verbal memorization alone, but also requires an understanding of the phenomena of submicroscopic representation of the structure of molecules or atoms (Coll \& Treagust, 2003; Davidowitz, Chittleborough \& Eileen,2010). A study by Coll (2008) stated that the ability of participant learners to operate or use their mental models in order to explain the events that involve the use of submicroscopic representations is very limited, so there is a need for training in interpreting submicroscopic visual images through instruction that involves 3 levels of chemistry phenomena (macro, submicroscopic, and symbolic phenomena). The goal is that students are able to provide explanations and gain a deep conceptual knowledge, so that students can more easily solve problems associated with abstract concepts.

- $\quad$ performance improved as using information and communication tools in teaching particulate nature of matter provided students with a more student-centered and activity-based pedagogy, and enhanced conceptual understanding of structure of the atom. Using information and communication tools in teaching particulate nature of matter also helped maintain the quality of teaching and learning and ensured the lesson was delivered within the stipulated time. From the study, students who initially had the misconception that Chemistry is difficult were able to draw the structure of the atom with ease after information and communication tools were used to teach and were also able to interpret observations made by Rutherford on the structure of the atom without committing them to memory. Students' came together to share ideas in order to come out with solution to the various assignments given to them by the researcher. The use of information and communication tools made teaching and learning more interesting as students were motivated to learn. This made students' punctual in class and lateness was also avoided.

This study also sought to improve student's academic performance by addressing the second research question that is, what effect does the use of information and communication tools in teaching particulate nature of matter have on the learning outcomes of students?

Data was collected in the pre-intervention stage and was compared with the data collected after the 
intervention was implemented and analysed.

Table 1. The Comparison of Students' Mean Performance in Knowledge, Comprehension and Analysis of Pre-test and Knowledge, Comprehension and Analysis of Post-test

\begin{tabular}{lcccccc}
\multicolumn{1}{c}{ Mest } & $\mathrm{N}$ & Std. Deviation & t-value & df. & p-Value \\
\hline Post-test (knowledge) & 4.9143 & 35 & 1.59727 & & & \\
Pre-test (knowledge) & 2.2857 & 35 & 1.54485 & & & \\
& & & & & & \\
\hline Post-test (Comprehension) & 5.0571 & 35 & 1.73108 & & & \\
Pre-test (Comprehension) & 1.6571 & 35 & 1.0 .2736 & & & 0.000 \\
\hline Post-test (Analysis) & 3.0857 & 35 & 0.78108 & & & \\
Pre-test (Analysis) & 1.1714 & 35 & 1.12422 & & & 0.000 \\
\hline
\end{tabular}

From Table 1, the mean knowledge in post-test is 4.9143 and the mean knowledge in pre-test is 2.2857. The $\mathrm{p}$-value is 0.000 . Since the p-value is less than 0.05 , it means there is a statistical difference between the mean knowledge in pre-test and mean knowledge in post-test. Comparison of students' mean achievement showed that student's knowledge in the structure of atom during the post-test was higher than the pre-test.

More also, the mean comprehension in post-test is 5.0571 and the mean comprehension in pre-test is 1.6571 . The $\mathrm{p}$-value is 0.000 . Since the $\mathrm{p}$-value is less than 0.05 , it means there is a statistical difference between the means comprehension in pre-test and mean comprehension in post-test. Comparison of students' mean achievement showed that student's comprehension in the structure of atom during the post-test was higher than the pre-test.

Finally, the mean analysis in post-test is 3.0857 and the mean analysis in pre-test is 1.1714 . The p-value is 0.000 . Since the $p$-value is less than 0.05 , it means there is a statistical difference between the means analysis in pre-test and mean analysis in post-test. Comparison of students' mean achievement showed that student's analysis in the structure of atom during the post-test was higher than the pre-test. This study has found out that the students' performance increased when ICT was used in teaching the structure of the atom. This study has found out that the students' performance increased when ICT was used in teaching in the lessons.

Table 2. The Comparison of Students' Mean Performance in Pre-test and Post-test

\begin{tabular}{lllcccc}
\hline Test & Mean & N & Std. Deviation & t & df & P-value \\
\hline Post-test & 13.1429 & 35 & 3.33557 & & & \\
& & & & 18.638 & 34 & 0.000 \\
Pre-test & 5.0286 & 35 & 2.66222 & & & \\
\hline
\end{tabular}

From Table 2, the mean of post-test is 13.1429 and the mean of pre-test is 5.0286. The p-value is 0.000 . Since the p-value is less than 0.05 , it means there is a statistical difference between the means of post-test and pre-test. The comparison of students' mean achievement showed that the post-test was higher than the pre-test. It was concluded that there was a significant difference in achievement of students in the structure of the atom. This indicated that the performance of students in knowledge, comprehension and analysis were all increased when teacher used ICT tools in teaching the structure of the atom.

As a result of the use of ICT tools in teaching, student's performance improved. Students were able to explain why an atom is said to be electrically neutral and they were able to interpret why most alpha particles passed through the nucleus of a thin gold without deflection, why most of the alpha particles deflected through large angles and why a few alpha particles bounced back. As far as students' performance on knowledge, comprehension and analysis is concerned, it was inferred that the performance of students on the structure of the atom in the posttest after the intervention has improved as compared to pre-test before the intervention. Based on the findings from the pre-test and post-test when science teachers use ICT tools to teach particulate nature of matter and understand how to use these technologies into their teaching, value is added to the learning environment and students are afforded the opportunity to improve their learning outcomes. ICT tools used in teaching particulate nature of matter can assist weaker students to make progress as the learning material can be directed at the level appropriate for each student and they will be motivated to learn. This finding is supported by Yusuf (2005) who revealed that ICT 
tools have the potential to accelerate, enrich and motivates students to learn. In addition, ICT tools also provide a richer and more exciting learning environment for teaching and learning (Jonassen, 2002). Video presentation of concepts with the aid of Projector will make teaching livelier and more interesting which will intend motivates students to learn. According to Haddad and Jurich (2002) the use of ICT tools, in particular computer technologies, is correlated to positive academic outcomes, including higher test scores, better attitudes towards schools, and better understanding of abstract concepts. Many studies have described the motivating effect of using ICT tools in schools and the positive effect it can have on student's attention and effort in class. Trimmel and Bachman (2004) studied the impact of introducing laptops into classrooms and one of their conclusions was that ICT tools have a positive impact on school attendance and learning interest. The DfES (2003b) drew on a number of research projects to support its statement that ICT can play an important role in motivating pupils and encouraging them to engage in learning within and beyond the classroom.

\subsection{Qualitative Phase of Analysis}

6.2 Report on the Structure of Atom

Information and communication tools used in this lesson includes: computer and a projector

Activity 1: why an atom is said to be electrically neutral

Students could not explain why an atom is said to be electrically neutral. The researcher opened the image and asked students to count the number of protons, neutrons and electrons in the image.

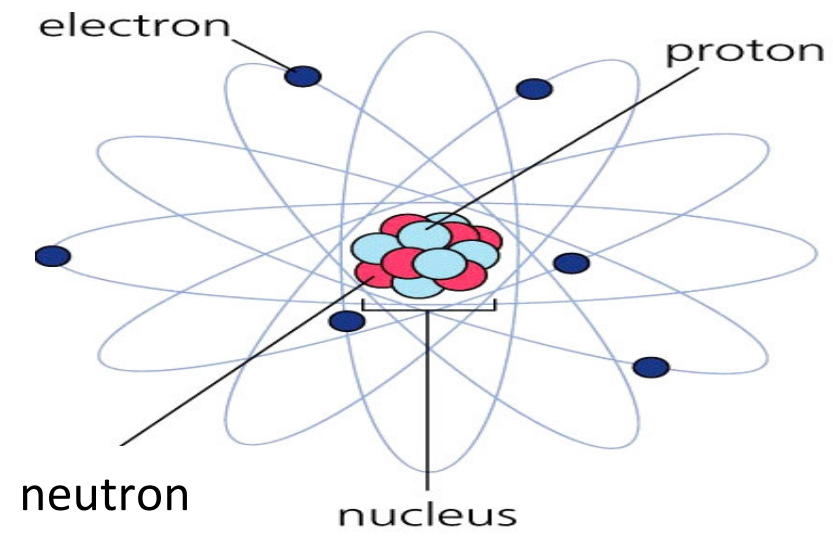

Figure 1: Structure of the Atom (Sarong, 2007)

Researcher: How many protons are in the atom?

The students gave an answer as 6.

Researcher: How many electrons are in the atom?

Students' response: 6

Researcher: How many neutrons are in the atom?

Students' response: 6

The researcher asked students to state the charges of proton, neutron and electron

Students' response:

Proton has a charge of $(+1)$, neutron has no charge and electron has a charge of $(-1)$

Researcher: What is the net charge of the atom in Fig. 1 which has 6 proton, 6 neutrons and 6 electrons?

Students' response: the net charge of the atom is 0.

Researcher: Why is an atom said to be electrically neutral?

Students' response: The negatively charge electrons and positively charge protons of a neutral atom are the same hence they cancel out and makes an atom electrically neutral.

Activity 2. Identifying mass number and atomic number of Atom

The Researcher opened an image showing the representation of three isotopes of hydrogen on the projector and asked students to identify the mass numbers and atomic numbers of Hydrogen. 


\section{AX}

$\mathrm{A}=$ Mass number $\mathrm{Z}=$ Atomic number

\begin{tabular}{ccc}
${ }_{1}^{1} \mathrm{H}$ & ${ }_{1}^{2} \mathrm{H} \equiv \mathrm{D}$ & ${ }_{1}^{3} \mathrm{H} \equiv \mathrm{T}$ \\
protium & deuterium & tritium \\
\hline
\end{tabular}

Figure 2: Representation of the Atom (Sarong, 2007)

Students' response: Mass number (A) is placed as a left superscript on the chemical symbol of an element and Atomic number $(Z)$ is placed as a subscript on the chemical symbol of an element. Hence the mass number of Protium is 1 and its atomic number is 1 , the mass number of deuterium is 2 and its atomic number is 1 and the mass number of tritium is 3 and its atomic number is 1 .

Researcher: what is the mass number and atomic number in the atom $\mathrm{Cl}$ ?

Students' response: mass number is 35 and atomic number is 17

\subsection{Findings from lesson on the Structure of Atom}

Students were able to

- $\quad$ explain why an atom is said to be electrically neutral as a neutral atom has the same number of protons and electrons hence their net charges cancel out making an atom electrically neutral.

- identify that mass number is always written as a superscript and atomic number is also written as a

\section{Report on Matter} subscript by the chemical symbol of every element.

Researcher: what is a Molecule?

Students' response: A molecule is composed of two or more atoms that are chemically combined.

Activity 1: Formation of a Molecule

Researcher: How is a Molecule formed?

Students were not able to answer the question.

The researcher projected an image showing how two atoms of hydrogen combine to form hydrogen gas (molecule) and discussed with students how molecules are formed from atoms.

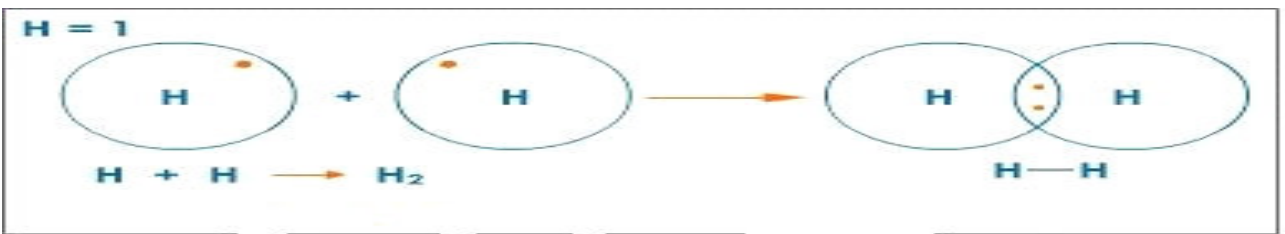

Figure 2: Formation of hydrogen gas (molecule) (Sarong, 2007)

The researcher pressed on the keyboard and an image popped up showing addition of two atoms of hydrogen. The researcher asked student to explain what will happen when on atom of hydrogen is added to another one atom of hydrogen. The students explain that the two atoms will combine to form hydrogen molecules. The researcher then pressed on the next key and an arrow with the image of hydrogen molecule popped up. The researcher explained to students that when two or more atoms combines chemically a molecule is formed.

Activity 2: Formation of an Ion

Researcher: What is an Ion?

Students' response: An ion is an electrically charged atom.

Researcher: How is an ion formed from an atom?

Students were not able to answer the question.

The researcher projected an image showing how an ion is formed from an atom and discussed with students how ions are formed from atom. 


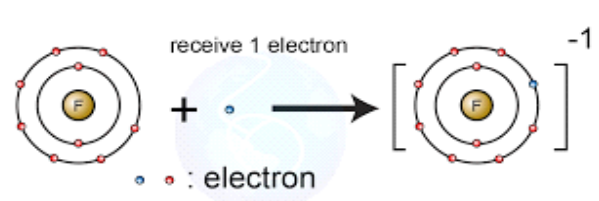

Number of proton $=9$ Number of electrons $=9$ Charge $=0$ (Neutral)
Number of proton $=9$ Number of electrons $=10$ Charge $=-1$

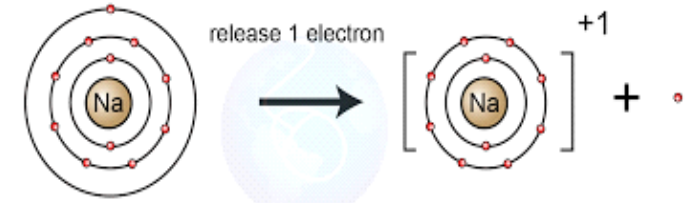

Number of proton $=11$

Number of proton $=11$ Number of electrons $=11 \quad$ Number of electrons $=10$ Charge $=0$ (Neutral)

Figure 3: Formation of an ion (Sarong, 2007)

The researcher asked students to describe what they see in the image.

Students' responses: The atom has a total of 9 electrons around the nucleus. Electrons in the outer shell are 7 and electrons in the inner shell are 2.

The researcher pressed on the next key and an arrow with another image popped up. The researcher asked students to describe the image.

Students' response: the atom has gained an electron hence it has a total of 10 electrons. The outermost shell has 8 electrons and the innermost shell has 2 electrons. It has a charge of -1 .

The researcher asked the students to explain why the atom has a charge of - 1 . The students explained as the addition of an extra electron made the atom electrically charged.

The researcher pressed on the next key and asked the students to describe the image that popped up.

Students' response: The atom has a total of 11 electrons with only one electron in the outermost shell. It has no charge.

The researcher pressed on the next key and an arrow with another image popped up. The researcher asked students to describe the image.

Students' response: the atom has lost one electron hence it has a total of 10 electrons. It also has a charge of +1 . The researcher asked the students to explain why the atom has a charge of +1 . The students explained as the loss of an electron in the outermost shell made the atom electrically charged.

The researcher then opened an image showing how chlorine atoms forms chloride ion and ask students to explain.

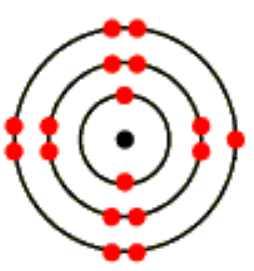

chlorine atom,

Cl $2,8,7$

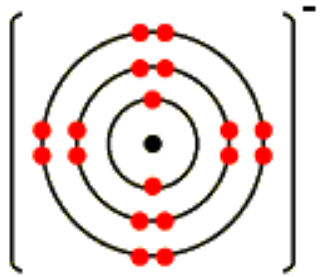

chloride ion,

$\mathrm{Cl}^{-}[2,8,8]^{-}$

Figure 4: Formation of chloride ion (Sarong, 2007)

Student's response: Chlorine atom has 17 protons in the nucleus and 17electrons surrounding it. Chlorine gains one electron into the outermost shell in other to gain stability. Gain of one electron makes it chloride ion. This means there are 17 protons and 18 electrons. Chloride ion now has a net charge of -1 .

\subsection{Findings from lesson on Matter and Ion}

Students were able to

- $\quad$ explain that molecules are formed as when two or more atoms of the same elements or different elements combine chemically

- $\quad$ explain that ions are also formed when an atom loose or gain electrons. An atom loses an electron to become positively charged and are called cation and gains electron to become positively charged and are called anion.

\section{Report on Rutherford Structure of Atom}

Information and communication tools used in this lesson includes: computer and a projector.

Activity 1: Description of Rutherford Alpha scattering experiment of Atom

The researcher downloaded images showing Rutherford's alpha scattering experiment on his computer. The researcher then projected and scroll through the images showing the various parts of the alpha scattering experiment.

The researcher opened image I on the projector and asked students to identify the part labeled I. Some students gave an answer to I as cube. The researcher then pressed on the next key and an arrow with the name of the part labeled I popped up as Source of alpha particles. The Researcher pressed on the next key and asked students to 
identify II. Some of the students mentioned a circle. The researcher pressed on the next key and arrow with an answer of the part labeled II popped up as circular fluorescence screen. The researcher pressed on the next key and asked students to identify the part labeled III. A student gave an answer as a yellow rectangle. The researcher then pressed on the next key and an arrow with an answer of the part labeled III popped up as a thin gold foil.

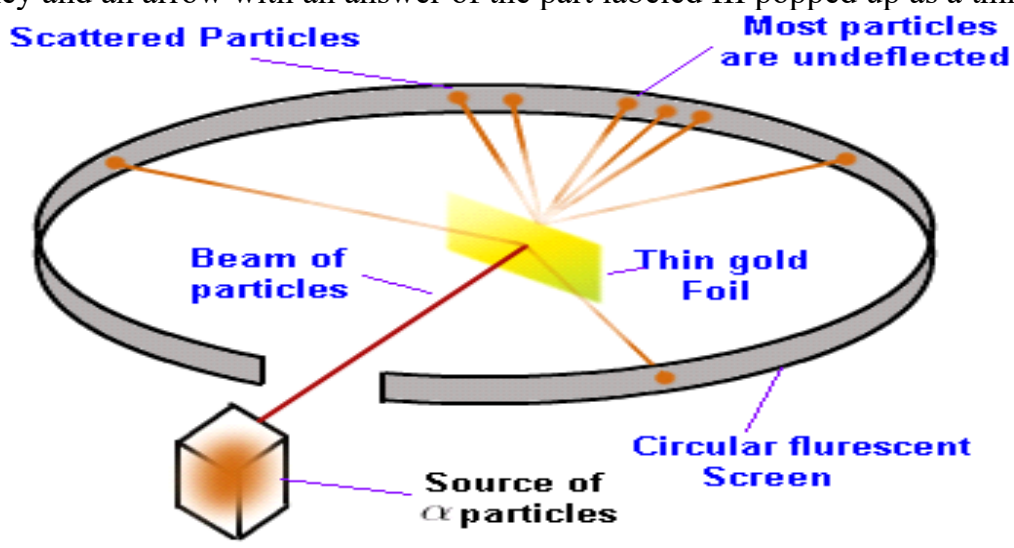

Figure 4: Image of Rutherford's Alpha Scattering Experiment (Tyler, 2012)

The researcher downloaded a video showing how Rutherford's alpha scattering experiment by Tyler (2012) projected the video and played with VLC media player for students to watch. The video explains how alpha particles were made to bombard the nucleus of the thin gold foil.

Most of the alpha particles passed through the nucleus of the gold without deflecting. A few of the alpha particles deflected through large angles. A small portion of the alpha particles bounced back.

Activity 2: Observations from the experiment

The researcher opened image 9 showing how the alpha particles were being deflected on their computer.

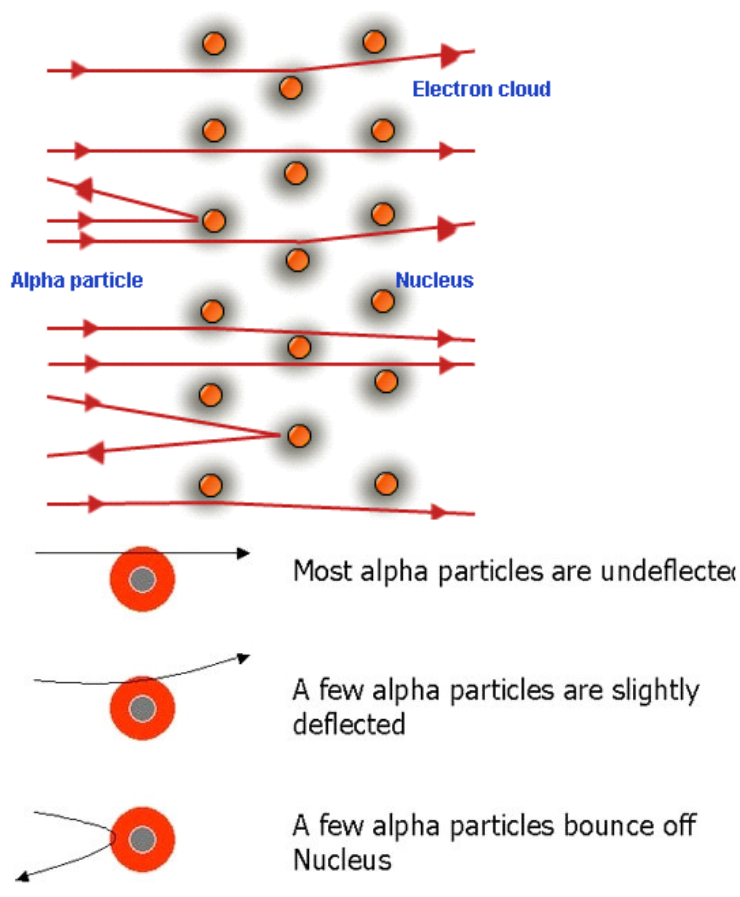

Figure 5: Deflection of Alpha Particles (Tyler, 2012)

Researcher: What interpretation can be made from the observations?

Students' responses:

- most of the volume of the atom is empty space occupied by electrons which are light to deflect alpha particles

- deflection through large angles were as a result of repulsion of the alpha particles which came very close to a concentrate region of positive charge.

- alpha particles bounced back as a result of 'head on' collision with massive positively.

Activity 3: Description of Rutherford's structure of Atom

Students opened image of Rutherford's structure of atom. 
Researcher: How does Rutherford model of the atom looks like?

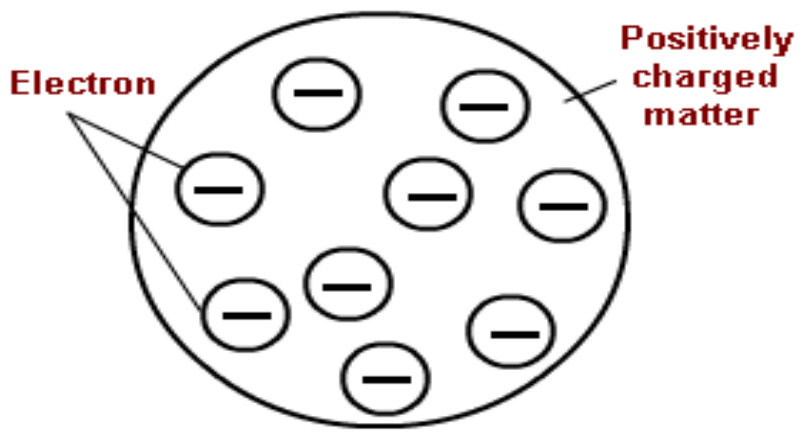

Figure 6: Rutherford's Model of the Atom (Tyler, 2012)

Students' response:

- The atom has a central positive nucleus composed of protons where all the mass is concentrated.

- The electrons in the atom orbit around the nucleus

- The greater portion of the atom is an empty space occupied by electrons.

The researcher asked students to draw Rutherford structure of Atom and award marks.

\subsection{Findings from lesson on Rutherford Structure of Atom}

Students were able to

- $\quad$ explain Rutherford's alpha scattering experiment on the atom.

- interpret the observations as most of the volume of the atom is empty space occupied by electrons which are light to deflect alpha particles, deflection through large angles were as a result of repulsion of the alpha particles which came very close to a concentrate region of positive charge and alpha particles bounced back as a result of 'head on' collision with massive positively.

- describe Rutherford's structure of atom as an atom has a central positive nucleus composed of protons where all the mass is concentrated and electrons in the atom orbit around the nucleus.

\subsection{Summary of findings}

The study sought to find out student's learning outcomes when ICT tools are used in teaching particulate nature of matter at GESHS form one class in the Techiman North District in the Brong-Ahafo Region. The major findings in this study which spanned five lessons on the structure of atom were as follows:

- The students were able to describe the characteristics of the states of matter through the use of animated images which described solids as having a definite shape and size, liquids having definite volume but do not have fixed shape and gases do not have definite shape and volume.

- The students were able to identify the sub-atomic particles of atoms as proton, neutron and electron and were able to identify the position of the nucleus through the use of pictures which showed nucleus as the center of an atom which contains protons and neutrons whilst electrons move around the nucleus.

- The students were able to identify parts of the cathode ray tube through animated pictures which showed the parts of the cathode ray tube as High voltage, electric field, magnetic field and fluorescence screen.

- The students were able to explain how Thompson discovered the electron from the cathode ray tube and describe Thomson's structure of Atom through the use of video which showed how the electrons were discovered.

- $\quad$ The students were able to explain Rutherford's alpha scattering experiment of the atom through the use of video which described Rutherford's scattering experiment and structure of Atom as having a central positive nucleus composed of protons where all the mass is concentrated and electrons in the atom orbit around the nucleus.

- $\quad$ The students were able to explain why an atom is said to be electrically neutral through the use of animated images which shows how protons and electrons cancels out to make an atom electrically neutral.

- $\quad$ The students were able to identify mass number and atomic number of an element through the use of pictures which showed mass number written as a superscript and atomic number as a subscript by the chemical symbol of every element.

- The students were able to explain that molecules and ions are formed through the use of pictures which showed how molecules and ions are formed from an atom. 


\section{Conclusion}

One purpose of Science Education is to ensure that learner understand Science concepts and be able to apply it to human's need. The study revealed that students from GESHS did not understand structure of the atom because they could not visualise it because it was taught abstractly hence leading to their poor performance.

However, the use of ICT tools in teaching particulate nature of matter illustrated how it provided a learning environment where students were given effective opportunity to visualise, abstract concepts. For instance, images and videos that were projected helped students to see the parts of the cathode ray tube and how cathode rays were emitted from the cathode through the anode to the fluorescent screen detector. After watching the video, students were able to explain how electrons were discovered from the cathode ray tube without committing them to memory. The use of ICT tools in teaching and learning helps students to expand knowledge, experience and increase understanding, especially in the Science subjects that require visual, audio, flow chart, video presentation and so on.

The findings concluded that using ICT tools in particulate nature of matter has positive impact on students' achievements. Schools must strive to increase usage of ICT tools amongst teachers. Besides, teachers should put more effort to use ICT tools in their Science lesson in order to increase students' achievements. Teachers who are weak in the use of ICT tools in teaching need to participate in ICT training courses. ICT facilities provided by the government in schools must be fully utilised by the teachers.

Using ICT tools in teaching can also help students to understand concepts through a relationship with a reallife situation. The use of ICT tools in teaching particulate nature of matter can improve students' achievements compared to using traditional approaches. Moreover, it can make teaching and learning process become more interesting, encouraging and effective. Using ICT tools in teaching encourages students to process information better and thus enhances the understanding and improves students' memory. In addition, the use of ICT tools in teaching will motivate the learners and hence develop favourable attitude towards science subject.

The overall conclusion from this study reveals that ICT tools has a significant and positive impact on teaching and learning specifically for Science subject. ICT tools contributes greater performance or achievement of students. Teachers should replace traditional teaching approach with attractive learning style by involving ICT tools in their lesson. Science field that needs investigation and practical works needs ICT tools to assist in teaching.

\section{Recommendation}

Based on the findings of the study, and the availability of the ICT tools in the school, the following recommendations were made to enhance the teaching and learning of the particulate nature of matter. It is recommended that:

- teachers in the school should use ICT tools to show images and animation which describes the characteristics of the states of matter in order for students to see how particles in the solid, liquid and gases behaves.

- teachers in the school use ICT tools to show images and animation which describes how sub-atomic particles are arranged in an atom for students to be able to identify the position of each subatomic particle.

- teachers in the school need to be aware that the structure of atom as proposed by J. J. Thomson, Lord Rutherford is not readily comprehensible to students' so it is recommended that they should use ICT tools to project images and videos (animation) showing how electrons were discovered from the cathode ray tube experiments and the structure of atom proposed by J. J. Thomson.

\section{References}

Ansah, O. G. (2015). The effect of constructivist instructional approach Students' performance in chemical bonding concepts. Winneba: University of Education, Winneba.

Çimer, A. (2004). Effective Teaching in Science: A Review of Literature. J. Turkish.

Coll, R.K. (2008). Chemistry learners preferred mental models for chemical bonding. Journal of Turkish Science Education, 5, (1), $22-47$.

Coll, R.K. \& Treagust, D. F. (2003). Investigation of secondary school, undergraduate and graduate learners' mental models of ionic bonding. Journal of Research in Science Teaching, 40, $464-486$.

Davidowitz, B., Chittleborough, G.D., \& Eileen, M. (2010). Student-generated submicro diagrams: A useful tool for teaching and learning chemical equations and stoichiometry.Chem. Educ. Res. Pract., 11, 154-164.

De Jong, O., \& Taber, S. (2007). Teaching and Learning the Many Faces of Chemistry in S. K. Abell \& N. G. Lederman (Eds.), Handbook of Research on Science Education (pp.631-652). Mahwah, New Jersey: Lawrence Erlbaum Associates.

DfES (2003b). The big picture: the impact of ICT on attainment, motivation and learning. Nottingham: DfES.

Francisco, J. S., Nakhleh, M. B., Nurrenbern, S. C., \& Miller, M. L. (2002). Assessing student understanding of general chemistry with concept mapping. Journal of Chemical Education, 79(2), 248-257.

Huffman, D., Goldberg F., Michlin M. (2000). Using Computers to Create Constructivist Learning Environments: 
impact on pedagogy and achievement. Journal of Computers in Mathematics and Science Teaching, 2(2), 151-168.

Jonassen, D. (2002). Learning with technology: Using computers as cognitive tools. In: Jonassen DH, eds. Handbook of Research for Educational Communications and Technology (693-719). New York, NY: Macmillan.

Kothari, C.R. (2004). Research methodology: methods and techniques (2nd Revised ed.). New Delhi: New Age International.

Krah, K. P. (2014). Effect of self-learning and computer assisted instructional approaches in improving academic performance of home economic students in some selected biology concepts at Wenchi Senior High School. Winneba: University of Education, Winneba.

Mayer, R. E. (2009). Multimedia Learning (2nd Edition), New York: Cambridge University.

Niaz, M., Aguilera, D., Maza, A., \& Liendo, G. (2002) Arguments, contradictions, resistances, and conceptual change in students' understanding of atomic structure. Science Education, 86, 505-525.

Özcan, N. (2003). A Group of students' and teachers' perceptions with respect to biology Education at high school level, MA Dissertation, Middle East Technical University, Ankara, Turkey.

Park, E. J., \& Light, G. (2009). Identifying atomic structure as a threshold concept: Student mental models and troublesomeness. International Journal of Science Education, 31(2), 233-258.

Saka, A. (2006). The effect of 5 e model on removing science student teachers' misconceptions about genetics, $\mathrm{PhD}$ Dissertation, Karadeniz Technical University, Trabzon Turkey.

Sarantakos, S. (2005). Social research (3rd ed.). New York, NY: Palgrave Macmillan.

Sarong, F. K. (2007). Physical chemistry for senior high schools. Accra: Anest Company.

Sze-yin, S. Y. (2015). Conception of teaching higher order thinking: perspectives of Chinese teachers in Hong Kong. The Curriculum Journal, 26(4) pg. 95.

Tchombe, T. M.S., Maiga, M., Toure, K., Mbangwana, M. A, Diarra, M. L., \& Karsenti, T. (2008). Gelling readyjar higher education: Role of ICT in secondary schools. Paper for the ADEA Biennale in Maputo, Mozambique.

Trimmel, M., \& Bachman, J. (2004). Cognitive, social, motivational and health aspects of students in laptop classrooms. Journal of Computer Assisted Learning, 20(2), 1551- 158.

Tyler, D. (2012). Discovery of the nucleus: Rutherford's gold foil experiment. Retrieved August 12, 2017 from http: // www. youtube. com/watch? $\mathrm{v}=\mathrm{dNp} \mathrm{vP17}$ asI\&feature=youtu.be

UNESCO. (2002). Information and communication technology in education: a Curriculum guide for schools and programs of teacher development. Division of Higher Education. Retrieved January 20, 2017, from http:// unesdoc . unesco.org/ images / 0012/001295/129538e.Pd

Wagner, A. D. (2001). IT and education for the poorest of the poor: Constraints, possibilities and principles. TechKnowLogia, 13, 48-50.

Yusuf, M.O. (2005). Information and communication education: Analysing the Nigerian national policy for information technology. International Education Journal, 6(3), 316-321.

Zeidan, A. (2010). The Relationship between grade 11 Palestinian attitudes toward biology and their perceptions of the biology learning environment. Int. J. Science Mathematics. Education, 8,783-800. 